\title{
Solid Dispersion of Usnic acid-HPMC 2910 Prepared by Spray drying and Freeze drying Techniques
}

\author{
LILI FITRIANI ${ }^{1}$, IRMA AFRIYANTI ${ }^{1}$, AFRIYANI ${ }^{1}$, FRIARDI ISMED ${ }^{2}$ and ERIZAL ZAINI ${ }^{\text {* }}$ \\ ${ }^{1}$ Deparment of Pharmaceutics, Faculty of Pharmacy, Andalas University, Padang, 26163, Indonesia. \\ ${ }^{2}$ The Laboratory of Natural Resource of Sumatra and Faculty of Pharmacy, Andalas University, \\ Padang, 26163, Indonesia. \\ ${ }^{*}$ Corresponding author E-mail: erizal @ phar.unand.ac.id
}

http://dx.doi.org/10.13005/ojc/3404048

(Received: May 23, 2018; Accepted: July 08, 2018)

\begin{abstract}
Usnic acid is a dibenzofuran derivate produced by some lichens species primarily Usnea sp., that has several pharmacological activities. Based on Biopharmaceutical Classification System (BCS), usnic acid belongs to class II that has high permeability but low solubility. Therefore, the purpose of this research was to increase the solubility of usnic acid by preparing solid dispersions (SD) using hydrophilic polymer HPMC 2910. Usnic acid and HPMC at ratio 1:1 (w/w) were prepared for solid dispersion using spray drying and freeze drying techniques. Physical mixture at the same ratio was prepared as comparison. Characterization for intact materials, physical mixture and solid dispersions were done using powder X-ray diffraction (PXRD), differential scanning calorimetry (DSC), scanning electron microscopy (SEM), fourier transform infra-red (FT IR) spectroscopy, and solubility test. The result of PXRD showed a decrease of peak intensity for solid dispersions. Thermal properties of solid dispersions showed lower melting point compared to usnic acid and physical mixture. The morphology of solid dispersion depicted different shape compared to intact materials and physical mixture. The infra-red spectrum showed the slightly shift at wave numbers of functional groups but there was no new functional groups formed. The solubility of solid dispersions significantly increased, which the solubility test result were $55 \pm 0.023,227 \pm 0.034,567 \pm 0.020$, and $932 \pm 0.053(\mu \mathrm{g} / \mathrm{ml})$ for intact usnic acid, physical mixture, SD by spray drying and SD by freeze drying, respectively. In conclusion, solid dispersions of usnic acid - HPMC 2910 were able to modify physicochemical properties and increased the solubility.
\end{abstract}

Keywords: Usnic acid, HPMC 2910, Spray drying, Freeze drying, Solubility dispersion.

\section{INTRODUCTION}

Usnic acid is a second metabolite of Usnea $s p$, which is a dibenzofuran derivate. Since the first isolation in 1844 , usnic acid has become the most extensively studied and commercially available lichen metabolite ${ }^{1}$. Usnic acid demonstrates many pharmacological effect such as anti immflamatory, anti fungal, anti tubercular and citotoxic activity ${ }^{1-4}$. However, the use of usnic acid in therapy is limited

This is an Open Access article licensed under a Creative Commons Attribution-Non Commercial-Share Alike 4.0 International License (https://creativecommons.org/licenses/by-nc-sa/4.0/), which permits unrestricted Non Commercial use, distribution and reproduction in any medium, provided the original work is properly cited. 
due to its low solubility in water. Usnic acid is categorized as practically insoluble in water, which is $0.01 \mathrm{~g} / 100 \mathrm{ml}$ at $25^{\circ} \mathrm{C}^{5,6}$. In particular, intra-molecular hydrogen bonds provide lipophilic properties in usnic acid. Due to its non-polar nature, usnic acid becomes difficult to be absorbed and the bio-availability in the body becomes limited, thereby decreasing pharmacological activity and therapy $y^{7,8}$.

Several previous studies have been reported to improve the physicochemical properties of usnic acid. The formation of inclusion complexes of usnic acid with $\beta$-cyclodextrin has been able to increase solubility and dissolution rate of usnic acid $^{9}$. The formation of usnic acid complexes with polyacrylamide polymers has also increased solubility and antimicrobial activity of usnic acid ${ }^{10}$. Delivery systems to target within organs have been reported through microsphere formation with biodegradable PLGA polymers and nanoencapsulation for cancer therapy ${ }^{11,12}$. The formulation of an acidic topical patch film with topically used skin collagen was reported to be used for therapeutic burns and wound healing ${ }^{13}$. Preparation of solid dispersion system is one of the popular techniques to improve solubility and dissolution rate of poorly soluble active pharmaceutical ingredients. A solid drugs in the carrier may be dispersed in the amorphous phase, fine crystalline particles or metastable polymorphs ${ }^{14,15}$. To the best of our knowledge, the formation of a solid dispersion of usnic acid with hidrophilic polymer has not been reported to date. In this study, preparation of solid dispersions usnic acid using hydrophilic polymer, HPMC 2910, is done to modify solubility of usnic acid and to compare the preparation methods used. Characterization of intact materials and solid dispersions is conducted by powder X-ray diffraction (PXRD), differential scanning calorimetry (DSC), Fourier transform infra-red (FT-IR) spectroscopy and scanning electron microscopy (SEM).

\section{EXPERIMENTAL}

\section{Materials}

Usnea sp. was collected from Mt. Merapi (West Sumatera, Indonesia) and the isolation procedure of usnic acid from Usnea sp was explained in previous work ${ }^{16}$. HPMC 2910 (Shin-Etsu Chemical, Japan), chloroform (Merck, Germany), ethanol (Bratachem, Indonesia), and distilled water.

\section{Preparation of solid dispersion by spray drying}

Solid dispersion was prepared at ratio of usnic acid and HPMC 2910 1:1 (w/w). HPMC was dispersed in $100 \mathrm{ml}$ of distilled water and usnic acid was wetted using $2 \mathrm{ml}$ of ethanol. Usnic acid was then dispersed and homogenized by magnetic stirrer. Prior the formation of solid dispersion, spray dryer apparatus was set as follow: inlet temperature $120^{\circ} \mathrm{C}$ and outlet temperature $60^{\circ} \mathrm{C}$, flow $35 \mathrm{~m}^{3} / \mathrm{h}$ and diameter of nozzle $0.7 \mathrm{~mm}$. The dried powder then was kept in a desiccator.

\section{Preparation of solid dispersion by freeze drying}

Freeze dried powder was prepared at the same ratio as spray dried powder and the same process until usnic acid was dispersed homogeneously in HPMC 2910. The mixture then was frozen using liquid nitrogen. Prior to primary drying process, the freeze dryer was set at $-20^{\circ} \mathrm{C}$ and the pressure was at $0.056 \mathrm{~atm}$. The primary drying was done for 12 hours and the secondary drying process was set at temperature $20^{\circ} \mathrm{C}$ for the next 12 hours. The dried powder then was taken out from the freeze drier flask and kept in a desiccator.

\section{Preparation of physical mixture}

Physical mixture of usnic acid and HPMC 2910 at the same ratio $1: 1(\mathrm{w} / \mathrm{w})$ was prepared by mixing physically in a jar. The physical mixture powder was kept in a desiccator.

\section{Powder X-ray diffraction (PXRD) analysis}

The crystallinity of intact materials, physical mixture and solid dispersions was analyzed using an X-ray diffractometer (X'Pert XRD Powder type PW 30/40 PANalytical, The Netherlands). Analyzed sample was put on the sample holder and the analysis was done at angle $2 \theta$ in a range of $5-70^{\circ}$. The analysis was carried out at room temperature and the diffractometer was set as follow: target metals $\mathrm{Cu}, \mathrm{K} \alpha$ filter, voltage $45 \mathrm{kV}$, and current $40 \mathrm{~mA}$.

\section{Differential Scanning Calorimetry (DSC) analysis}

A differential scanning calorimetry apparatus (SETARAM Type EVO-131, France) was used to analyze thermal properties of usnic acid, HPMC, physical mixture and solid dispersions. Small amount of analyzed sample was put on an aluminum pan which has been calibrated using Indium prior to measurement. The DSC apparatus was set at $30-250^{\circ} \mathrm{C}$ with the heat flow $10^{\circ} \mathrm{C} /$ minute. 


\section{FT Infra-red Spectroscopy analysis}

The infra-red spectroscopy analysis was done using a spectrophotometer (Perkin Elmer FT-IR, the USA). The absorption of analyzed samples was recorded at wavenumber $4000-600 \mathrm{~cm}^{-1}$. The analysis was done for intact materials, physical mixture and solids dispersions.

\section{Scanning Electron Microscopy (SEM) analysis}

The surface morphology of usnic acid, HPMC, physical mixture and solid dispersions was observed using a SEM device (HITACHI type S-3400N, Japan) by placing small amount of analyzed sample on the sample holder and the device has been set as follow: the voltage $10 \mathrm{kV}$ and current $12 \mathrm{~mA}$.

\section{Solubility test}

An excessive amount of intact usnic acid, physical mixture and solid dispersions was added in $100 \mathrm{ml}$ distilled water and the solubility test was done in a water bath shaker for 24 hours. The sample was then filtered using Whatman filter paper and the amount of usnic acid dissolved in distilled water was quantified by UV-Vis spectrophotometer (Shimadzu UV-1700, Japan) at $\lambda \max$ of usnic acid in distilled water $(283 \mathrm{~nm})$.

\section{RESULTS AND DISCUSSION}

\section{Powder X-Ray Diffraction (PXRD) analysis}

PXRD is primary instrument used to identify

and analyze the crystallinity of materials. This analysis involves high energy that derived from $X$-ray radiation. The crystalline phase will show the typical interference peaks on the diffractogram due to the regular arrangement of atoms in the crystal lattice. On the hand, the amorphous phase that has irregular arrangement will show broad interference peaks with one or two maxima ${ }^{17}$. Usnic acid has sharp interference peaks that indicates the crystalline phase, which can be seen in Fig. 1 and Table 1. Meanwhile, HPMC shows broad interferences which likely to be an amorphous phase. Spray dried of usnic acid and HPMC showed a decline of peak intensity. In addition, the peak intensity of solid dispersion by freeze drying showed more reduction in peak interferences at the same $2 \theta$. A significant reduction in peak diffraction intensity of solid dispersions proves that there is a decrease in the degree of crystallinity of solid phase of usnic acid.

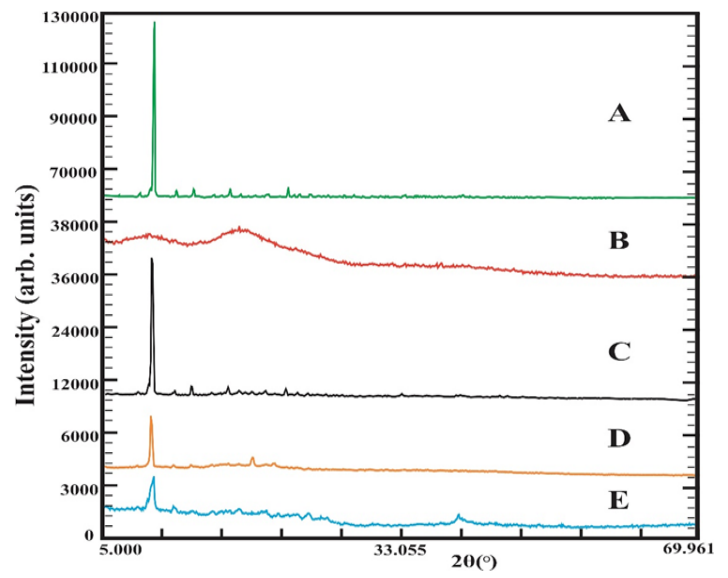

Fig. 1. Diffractogram of (A) usnic acid, (B) HPMC, (C) physical mixture (D) spray dried powder and (E) freeze dried powder

Differential Scanning Calorimetry (DSC) Analysis

DSC analysis is used to evaluate the thermodynamic properties of solid materials when exposed to thermal energy. The DSC thermogram will show the endothermic and exothermic peaks, due to the melting process, phase transition, recrystallization and dehydration (loss of water molecules) ${ }^{18}$. Usnic acid is a highly crystalline solid material, showing a sharp endothermic peak at $204^{\circ} \mathrm{C}$, which is attributed to its melting point, as shown in DSC thermogram Fig. 2. The HPMC polymer is an amorphous solid, showing an endothermic peak with a very wide range from 70 to $90^{\circ} \mathrm{C}$, which is the loss of water molecules temperature. The peak of endothermic of usnic acid in the physical mixture is still visible, although the melting point and the enthalpy of fusion are lower than intact usnic acid. The endothermic of usnic acid in the both solid dispersions significantly decreased compared to the physical mixture. This proves that preparation of usnic acid solid dispersion system with spray drying and freeze drying techniques causes the solid of usnic acid dispersed in the form of amorphous phase in HPMC hydrophilic polymer carrier ${ }^{18}$.

\section{FT-IR Spectroscopy analysis}

FT-IR spectrum of usnic acid, HPMC, physical mixture and solid dispersions is presented in Fig. 3. The spectrum shows usnic acid $\mathrm{O}-\mathrm{H}$ bond strain at wavenumber $3784.64 \mathrm{~cm}^{-1}$ and $\mathrm{C}-\mathrm{H}$ bond at wavenumber $2768.07 \mathrm{~cm}^{-1}$. HPMC shows the $\mathrm{C}-\mathrm{H}$ bond ay $2897.79 \mathrm{~cm}^{-1}$, which also in the range of $\mathrm{C}-\mathrm{H}$ bond $4000-3000 \mathrm{~cm}^{-1}$. Meanwhile, a shift in the wavenumber of physical mixture and solid dispersions is noticed, yet still in the range of the 
functional group wavenumber. The $\mathrm{O}-\mathrm{H}$ bond strain for physical mixture was at $3627.77 \mathrm{~cm}^{-1}$, solid dispersion by spray drying was at $3604.55 \mathrm{~cm}^{-1}$ and solid dispersion by freeze drying $3427.97 \mathrm{~cm}^{-1}$. In addition, a shift of the alpha $\mathrm{C}-\mathrm{H}$ group was also seen, which the wavelength for physical mixture, spray dried powder and freeze dried powder were $2892.42 \mathrm{~cm}^{-1}, 2894.69 \mathrm{~cm}^{-1}$, and $2895.15 \mathrm{~cm}^{-1}$, respectively. The infra-red spectrum dispersion confirmed no new peak in the wavelength which means no new functional group formed. This result indicated that solid dispersions did not involve a chemical interaction, but physical interaction ${ }^{16}$.

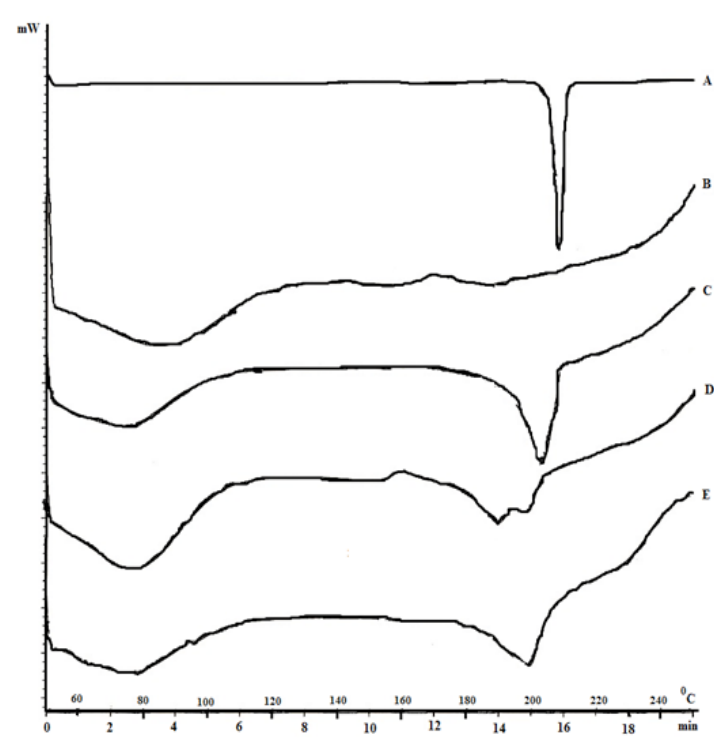

Fig. 2. DSC thermogram of (A) usnic acid, (B) HPMC 2910, (C) physical mixture, (D) spray dried particles, and (E) freeze dried particles

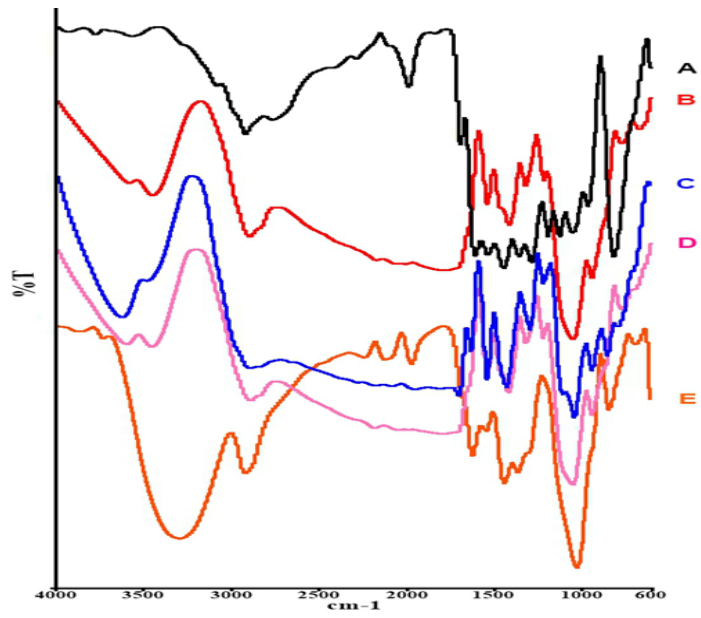

Fig. 3. Infra-red spectrum of (A) usnic acid, (B) HPMC, (C) physical mixture, (D) spray dried particles, and (E) freeze dried particles

\section{Scanning Electron Microscopy (SEM) analysis}

Scanning electron microscope is one of the most commonly instruments used to observe the morphology of materials due to its high resolution ${ }^{17}$. The result of SEM analysis would contribute to discussion about impact of process utilized in the materials. The morphology of intact materials, physical mixture, and solid dispersions is depicted in Fig. 4. As can be seen in Fig. 4a, usnic acid is shown as rod and HPMC looks an irregular particles (Fig. 1b). The physical mixture (Fig. 1c) shows both intact materials as the mixing process was conducted in lower energy which would not change morphology of particles. In contrary, the preparation of solid dispersion by both spray drying and freeze drying techniques alter the morphology of particles formed. The spray drying particles which prepared by utilizing nozzle in the spray dryer apparatus shows sphere particles (Fig. 1d). In addition, freeze drying techniques which applied sublimation process in the drying process generated the pores in the particles and particles has an irregular shaped (Figure 1e).
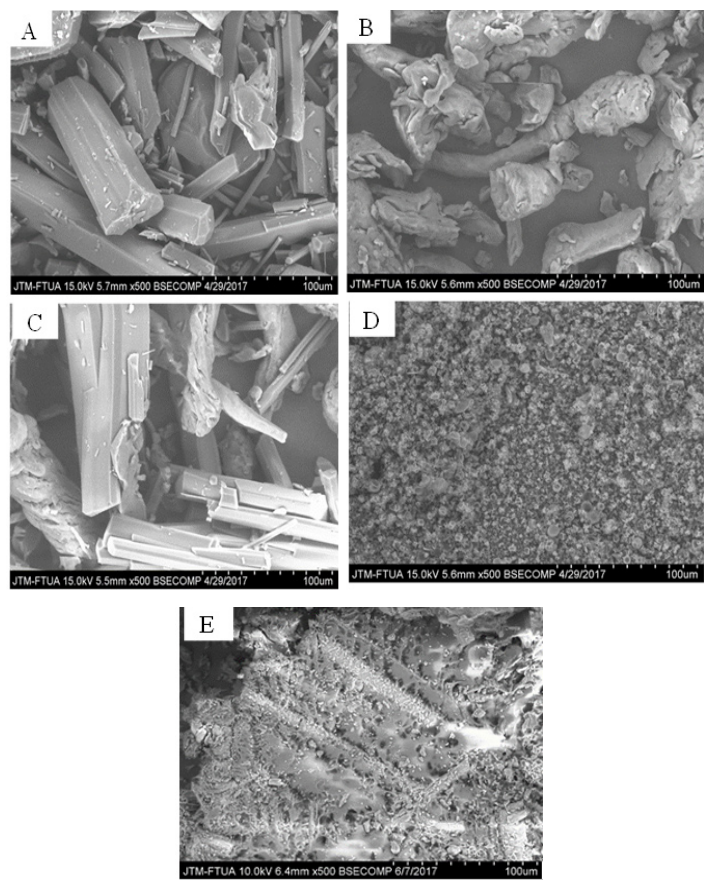

Fig. 4. The SEM microphotograph of (A) usnic acid, (B) HPMC 2910, (C) physical mixture, (D) spray dried particles, and (E) freeze dried particles

\section{Solubility Test}

The solubility of usnic acid, physical mixture and solid dispersions in distilled water is shown in Table 2. There was a remarkable increase in the 
solubility of usnic acid in solid dispersions, which is in agreement with the result of X-ray diffraction and thermal analysis. Several factors likely influence this solubility enhancement. Firstly, the impact of hydrophilic polymer, HPMC 2910, used in the physical mixture and solid dispersion has good solubility in water ${ }^{19}$. Moreover, the additional of HPMC correspond to the decreasing crystallinity of solid dispersions in particular, without forming or changing the functional new groups which proved in infra-red spectrum. The second reason is the methods used in solid dispersion preparations. Spray drying method is known to yield microsphere particles, as shown in microphotograph (Fig. 4), which contributes to the increasing the total surface area and solubility. Meanwhile, freeze drying method produces porous particles which also has impact when particles contact with water. Moreover, both methods utilized confirmed changes in thermal properties. As can be seen in the thermogram, the spray and freeze dried samples had lower endothermic properties. This result was expected as solid dispersions were prepared by mixing the usnic acid crystal with an amorphous polymer. Solubility plays an important role in the absorption process of active pharmaceutical ingredients in the gastrointestinal fluid, which is administered by oral route. Poorly soluble drugs often indicate bioavailability in the systemic circulation. Therefore, the modification of the solubility properties of drug compounds can significantly improve the bioavailability and pharmacological effectiveness. Solid phase and degree of crystallinity will affect solubility of poorly soluble drugs. Amorphous phase has higher solubility and dissolution rate than crystalline phase $\mathrm{e}^{14,15,20}$.

Table 1: Peak intensity of usnic acid, physical mixture and solid dispersions

Position $2 \theta$

Peak Diffraction Intensity

Usnic Acid Physical Mixture powder Spray Dried powder Freeze Dried powder

\begin{tabular}{lcccc}
\hline 10.24 & 91129.25 & 26450.39 & 6850.285 & 3036.947 \\
14.5817 & 3865.23 & 3571.058 & 1234.239 & 1112.269 \\
18.5911 & 3765.34 & 2001.297 & 1858.966 & 1117.999 \\
24.9268 & 5007.31 & 2375.888 & 1386.382 & 1006.275 \\
27.3058 & 2473.565 & 1649.55 & 1240.487 & 1145.207 \\
\hline
\end{tabular}

Table 2: Result of solubility test

\begin{tabular}{lc}
\hline Materials & Solubility $(\mu \mathrm{g} / \mathrm{ml})$ \\
\hline Usnic acid & $55 \pm 0.023$ \\
Physical Mixture & $227 \pm 0.034$ \\
Spray dried $(1: 1)$ & $576 \pm 0.020$ \\
Freeze dried $(1: 1)$ & $932 \pm 0.053$ \\
\hline
\end{tabular}

\section{CONCLUSION}

Solid dispersions of usnic acid and HPMC 2910 by both spray and freeze drying method enhance the solubility of usnic acid in water. Freeze dried powder has lower interference peak of crystallinity and endothermic properties compared to spray dried powder which contributes to the highest in the solubility.

\section{ACKNOWLEDMENT}

The authors would like to thank the Directorate-General of Higher Education, Ministry of Research, Technology and Higher Education Indonesia for research grant through the PUPT 2018.

\section{REFERENCES}

1. Yu, X.; Guo, Q.; Su, G.; Yang, A.; Hu, Z.; Qu, C.; Wan, Z.; Li, R.; Tu, P.; Chai, X. J. Nat. Prod., 2016, 79(5), 1373-1380.

2. Vijayakumar, C. S.; Viswanathan, S.; Reddy, M. K.; Parvathavarthini, S.; Kundu, A. B.; Sukumar, E. Fitoterapia., 2000, 71(5),564-566.
3. Ramos, D. F.; Almeida da Silva, P. E. Pharm Biol., 2010, 48(3), 260-263.

4. Bazin, M. A.; Le Lamer, A.C.; Delcros, J.G.; Rouaud, I.; Uriac, P.; Boustie, J.; Corbel J.C.; Tomasi, S. Bioorg. Med. Chem., 2008, 16(14), 6860-6866. 
5. Sokolov, D. N.; Luzina, O. A. E.; Salakhutdinov, N. F. Russ Chem Rev., 2012, 81(8), 747-768.

6. Ingolfsdottir, K. Phytochemistry., 2002, 61(7), 729-736.

7. Takai, M.; Uehara, Y.; Beisler, J. A. J. Med. Chem., 1979, 22(11), 1380-1384.

8. Cocchietto, M.; Skert, N.; Nimis, P.; Sava, G. Naturwissenschaften., 2002, 89(4), 137-146.

9. Nikolic, V.; Stankovic, M.; Nikolic, L.; Nikolic, G.; Ilic-Stojanovic, S.; Popsavin, M.; Zlatkovic, S.; Kundakovic, T. J Incl Phenom Macrocycl Chem., 2013, 76(1-2), 173-182.

10. Francolini, I.; Taresco, V.; Crisante, F.; Martinelli, A.; D'llario, L.; Piozzi, A. Int. J. Mol Sci., 2013, 14(4), 7356-7369.

11. Ribeiro-Costa, R. M.; Alves, A. J.; Santos, N. P.; Nascimento, S. C.; Gonçalves, E. C.; Silva, N. H.; Santos-Magalhães, N. S. J Microencapsul., 2004, 21(4), 371-384.

12. Lira, M. C.; Ferraz, M. S.; da Silva, D. G.; Cortes, M. E.; Teixeira, K. I.; Caetano, N. P.;
Santos-Magalhães, N. S. J. Incl Phenom Macrocycl Chem., 2009, 64(3-4), 215-224.

13. Nunes, P. S.; Albuquerque-Junior, R. L.; Cavalcante, D. R.; Dantas, M. D.; Cardoso, J. C.; Bezerra, M. S.; Souza, J.C.C.; Serafini, M.R.; Quitans-Jr, L.J.; Bonjardin, L.R.; Araújo, A. A. BioMed Res. Int., 2011, 50, 1-9.

14. Chiou, W. L.; Riegelman, S. J. Pharm. Sci., 1971, 60(9), 1281-1302.

15. Dwi, S.; Febrianti, S.; Zainul, A.; Retno, S. Marmara Pharm. J., 2018, 22(2), 259-266.

16. Zaini, E.; Nisak, R. K.; Utami, R. D.; Fitriani, L.; Ismed, F. Orient. J. Chem., 2017, 33(6), 3031-3036.

17. Newman, A. W.; Byrn, S. R. Drug Discov Today., 2003, 8(19), 898-905.

18. Baird, J. A.; Taylor, L. S. Adv. Drug Del. Rev., 2012, 64(5), 396-421.

19. Zaini, E., Fitriani, L., Effendy, S., Noviza, D., \& Halim, A. Orient. J. Chem., 2017, 33(2), 873-878.

20. He, X.; Pei, L.; Tong, H. H.; Zheng, Y. AAPS Pharmscitech., 2011, 12(1), 104-113. 